
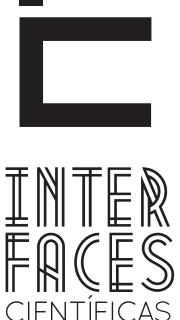

HUMANASE SOCIAIS

\title{
A LEITURA ILUMINISTA DE KANT E HEGEL PARA A INTERPRETAÇÃO DA HISTÓ́RIA UNIVERSAL
}

Sérgio Eduardo Lima Prudente ${ }^{2}$

\section{RESUMO}

0 objetivo deste artigo é realizar um percurso panorâmico por dois pontos de partidas que fundamentam compreensões e racionalidades que embasam leituras acerca da História universal. A partir dessa chave de leitura podemos vislumbrar dois modos predominantes de interpretação da História universal marcados por dois filósofos, a saber, Immanuel Kant e Friedrich Hegel. Cada um desses autores fundamenta seus programas teóricos com noções de Razão e História que marcam distinções no modo de compreender e interpretar a processualidade do tempo e da trajetória do homem na cultura.

\section{PALAVRAS-CHAVE}

História Universal. Razão. Fio Condutor. Kant. Hegel.

\section{ABSTRACT}

The purpose of this article is a scenic route by two starting points that underlie understandings and rationales based on reading about Universal History. From this, we can see a key to reading two predominant ways of interpretation of Universal History marked by two philosophers, namely, Immanuel Kant and Friedrich Hegel. Each of these authors based their programs with theoretical notions of Reason and History that mark distinctions in order to understand and interpret the processuality time and trajectory of human culture.

\section{KEYWORDS}

Universal History. Reason. Conducting Wire. Kant. Hegel 


\section{RESUMEN}

El objetivo de este artículo es realizar una ruta panorámica por dos puntos de partida que subyacen a entendimientos y razones que sostienen la lectura acerca de la Historia universal. Partiendo de esta clave de lectura se pueden visualizar dos formas predominantes de interpretación de la Historia universal, marcados por dos filósofos, que son Immanuel Kant y Friedrich Hegel. Cada uno de estos autores basan sus programas teóricos con las nociones de Razón e
Historia que marcan diferencias en el modo de comprender e interpretar la procesualidad del tiempo y la trayectoria del hombre en la cultura.

\section{PALABRAS CLAVE}

Historia Universal. Razón. El Alambre Conductor. Kant. Hegel

\section{INTRODUÇÃO}

No domínio da estética, Kant (2005) formula uma relação desinteressada do prazer estético que se dá em relação à representação da existência do objeto. Apesar desse prazer ser intrínseco, a faculdade de desejo, quando tratamos do juízo que determina o belo, a existência de tal prazer já não importa, o que interessa é apenas o juízo cujo "princípio transcendental é aquele pelo qual é representada a priori a condição universal, sob a qual apenas as coisas podem ser objetos do nosso conhecimento em geral" (KANT, 2005, p. 25).

Por outro lado, em sua Enciclopédia Das Ciências Filosóficas Em Epítome (1988), Hegel traz uma ideia que coloca em movimento a relação de interesse no homem, dando a ideia de uma individualidade subjetiva efetivada na atividade que afirma o sujeito na ação.

Esta distinção de perspectivas acerca do "interesse" serve como estratégia para se tomar a dimensão da história e da leitura dos textos gregos como objetos do interesse dentro de duas perspectivas fundamentais na filosofia da história.

A proposta aqui apresentada é que o "interesse" marca lugares a partir dos quais seguem linhas ra- cionais provenientes de certas tradições filosóficas, sendo as principais as de Kant e Hegel. Estes autores se referem à filosofia da história como tal e tratam de modo específico o assunto. Por isso, são os principais arquitetos dos programas de interpretação da história, nos quais podemos encontrar a marca do "interesse" desses autores, como uma espécie de tradição que forma um modo de compreensão da História Universal.

O objetivo é colocar a perspectiva essencial das visões de filosofia da história em Kant e Hegel, ou seja, introduzir, aqui, uma interpretação iluminista da história própria destes autores. Logo, são apresentados as duas visadas deste texto, a saber, o ponto de vista iluminista kantiano e hegeliano da filosofia da história e a forma como isso incidirá na interpretação de textos antigos.

Kant e Hegel privilegiam a razão. Esta obvia observação contém uma diferença básica entre os autores. Kant parte da razão transcendental, pura e prática como modo de alcançar a autonomia e a liberdade através de uma Lei moral que rege as ações; Hegel considera a razão como um elemento do espírito, imanente em cada indivíduo, e que faz parte de um 
grande projeto de efetivação do espírito (Geist) pela sua autoconsciência. Estas racionalidades em suas distinções introduzem duas maneiras de interpretar a história, mas que deixam claro o elemento central que sustenta os programas teóricos de ambos os autores, a saber, a Razão.

A história, portanto, é pensada por Kant e Hegel a partir dos processos ordenados pela Razão. Ponto de partida este que evidencia o caráter iluminista presente nas filosofias da história desses autores e que conduzem uma forma definida de leitura de textos e elementos históricos.

\section{KANT E O FIO CONDUTOR A PRIORI DA RAZÃO NA HISTÓRIA UNIVERSAL}

No capítulo IV da Doutrina Transcendental do Método (na Crítica da Razão Pura), Kant escreve sobre uma "história da razão pura". A escolha por iniciar deste ponto é para tentar situar a questão da história universal segundo o ponto de vista kantiano. No capítulo em questão Kant faz um voo panorâmico, do ponto de vista da Razão Pura, sobre os edifícios erguidos pela razão até aquele momento. Tais edifícios, segundo ele, em ruínas.

Logo de início, Kant já indica um aspecto fundamental de sua concepção de história: "Este título (História da Razão Pura) encontra-se aqui colocado para indicar uma lacuna que se mantém no sistema e que futuramente deverá ser preenchida." (KANT, 2001, p. 671). Ou seja, a história da razão pura indica um hiato em um sistema que futuramente será preenchido. Pode-se depreender disso uma ideia de um progresso que segue um fio condutor, uma racionalidade que ainda não alcançou sua transcendência, e a própria transcendência da razão pura que opera no sistema.
Dito isto, se faz necessário apresentar um panorama geral da filosofia da história de Kant e Hegel para melhor apreendermos a forma como a Razão pode manusear a história a partir de ângulos diferentes e de acordo com o "interesse" de uma racionalidade engendrada por estes autores. Como forma de organizar este trabalho, foi feita a opção por apresentar inicialmente Kant e em seguida Hegel, como forma de obedecer a uma cronologia na qual estes autores se situam. Ao final será apresentada uma breve discussão sobre o tema.

Kant deixa claro que não interessa especificar o tempo, mas propor um esboço da transformação na metafísica que demonstre as várias ideias que possibilitaram as revoluções. Nesse sentido, Kant chega a um triplo fim cujos passos foram dados em relação: 1) ao objeto dos conhecimentos da razão, onde Kant destaca os filósofos sensualistas (Epicuro, por exemplo) e intelectualistas (como Platão); 2) em relação à origem dos conhecimentos puros da razão, onde o problema consistia em saber se tais conhecimentos derivavam da experiência ou se tinha sua fonte na razão; 3) em relação ao método, onde este é o que procede segundo princípios que Kant divide em naturalista (segue o princípio da razão comum, sem ciência) e científico (que obrigatoriamente procede sistematicamente). Além desses três fins, Kant aponta ainda para a via crítica. Essa a única que permanece aberta e que representa o meio para resolver as questões metafísicas impostas pela razão.

0 que pode-se depreender destas marcas históricas que Kant chama de revoluções? Note que esta forma de organizar um fio condutor da história evi- 
dencia racionalidades operantes que avaliam, a partir de critérios, as coisas do mundo seguindo princípios sustentados no programa kantiano de uma razão pura transcendental. Isso demarca um ponto de vista ou de partida do filósofo em seu olhar para história.

Dito isto, passemos para o texto em que Kant tratou propriamente da história universal: Ideia de uma História Universal de um Ponto de Vista Cosmopolita.

Nas oito proposições deste texto, Kant sugere uma espécie de plano da natureza que opera ações seguindo princípios teleológicos que as justificariam. Está em jogo a liberdade das ações humanas e suas manifestações como acontecimentos naturais que seguem leis da natureza. Dessa forma, a história é a própria narrativa dessas manifestações, suas revoluções, rupturas e progressos. Têm-se, então, dois aspectos fundamentais a serem destacados: a natureza e suas leis como princípio a priori; e a história que, como narrativa das ações e manifestações, demonstra a própria razão do sistema. Kant não se interessa por compilações de elementos, nem as validades que poderiam justificá-los; a questão quantitativa da história, subjacente nesses aspectos é deixada de lado, pois o ponto em questão para o filósofo de Königsberg é a sistematização da história como uma unidade que, em seu desenvolvimento, segue uma razão.

Para Kant o homem é a única criatura racional na terra. Esta diferença marca a possibilidade de ocorrer um desenvolvimento da razão que o faça ultrapassar a existência animal. 0 homem não dispõe da racionalidade plena logo de saída, somente com a Razão é possível ampliá-la. No entanto, levar a razão ao uma plenitude levaria um tempo muito além do que individualmente um homem conseguiria viver. Isto corrobora o aspecto da espécie como meta principal do desenvolvimento. 0 fio condutor a priori parece conduzir um projeto inacabado de história que ainda tenta lidar com um conflito interno entre os elementos empíricos individuais e as disposições naturais da razão. Desta forma, tem-se por um lado a questão da liberdade como prática regulada por uma Lei moral sustentada na Razão Pura (programa sistemático da razão na natureza) e a ordenação mecânica da existência animal presente nas ações movidas pelas paixões e necessidades.

A liberdade, dessa forma, está condicionada ao esclarecimento da razão. Só por esta via o homem poderá ser feliz, pois encontrará a autonomia da liberdade da vontade fundada na razão:

\begin{abstract}
A natureza não faz verdadeiramente nada supérfluo e não é perdulária no uso dos seus meios para atingir seus fins. Tendo dado ao homem a razão e a liberdade da vontade que nela se funda, a natureza forneceu um claro indício de seu propósito quanto à maneira de dotá-la. (KANT, 2004 p. 6).
\end{abstract}

No entanto, Kant (2004) aponta para uma problemática no percurso da história: o antagonismo da insociável sociabilidade do homem. Em sociedade 0 homem pode desenvolver suas disposições naturais e assim se realizarem como homens; todavia, na medida em que ocorre o desenvolvimento, uma forte tendência a se separar se faz presente pela vontade de ditar a condução das coisas segundo suas próprias regras e para seu próprio proveito.

Disso resulta desde a preguiça até a ânsia de dominação. Entretanto, é necessário que isto ocorra para que haja os primeiros passos da cultura. 0 antagonismo possibilita o desenvolvimento das potencialidades do homem e a iluminação de um caminho onde se pode fundar um modo de pensar em que o patológico seja afastado da sociedade em relação ao todo moral. Kant (2004) destaca o antagonismo como uma espécie de princípio importante para o amadurecimento da espécie humana, sem ele a humanidade não atingiria uma finalidade. A natureza é o grande articulador do plano em que o antagonismo age para um fim. A ela Kant diz que devemos agradecer, pois pelo desejo insatisfeito de ter e dominar o ser humano não conseguiria desenvolver suas disposições: 
Os impulsos naturais que conduzem a isto, as fontes da insociabilidade e da oposição geral, de que advêm tantos males, mas que também impelem a uma tensão renovada das forças e a um maior desenvolvimento das disposições naturais. (KANT, 2004, p. 10).

Diante da conflitiva do antagonismo como alcançar uma sociedade civil que administre universalmente o direito? Esse é o problema definitivo da espécie humana, nele subjaz a solução do antagonismo de modo a possibilitar a coexistência livre dos membros da sociedade. Para Kant é necessário uma constituição civil perfeitamente justa, onde a liberdade está subordinada a leis exteriores e ligada a um poder irresistível. Esta é a mais elevada tarefa da natureza para espécie humana. Porém, o problema é que o homem necessita de um senhor para subordiná-lo às leis. Por este senhor estar à mercê das mesmas inclinações pessoais de qualquer outro homem, ele pode exceder-se e abusar da liberdade. Assim o supremo chefe tem que ser justo por si mesmo apesar de ser apenas um homem; tarefa difícil, mas que Kant encara como mais uma ordenação da natureza.

A tarefa da constituição civil será a última, para Kant (2004) isto decorre por que: 1) ela exige conceitos exatos da natureza da constituição civil; 2) exige grande experiência adquirida através dos acontecimentos do mundo; 3) exige uma boa vontade predisposta a aceitar essa constituição. Pela dificuldade de conciliar esses três pontos, a espécie humana ainda precisará esperar muito e passar por muitas tentativas frustradas.

0 problema de estabelecer uma constituição civil perfeita depende de que há necessidade de lidar com a relação externa legal entre Estados. 0 que Kant propõe aqui é que entre os Estados há um problema semelhante ao que há na relação entre os homens, ou seja, as incompatibilidades que geram os antagonismos entre os indivíduos, ocorrem entre os Estados.

Assim, o Estado precisa padecer do seu interior - dos egoísmos, invejas, ânsia de dominação, etc., - como forma de vivenciar preparativos e tentativas imperfeitas para finalmente

[...]sair do Estado sem leis dos selvagens para entrar numa federação de nações em que todo estado, mesmo o menor deles, pudesse esperar sua segurança e direito, não da própria força ou do próprio juízo legal, mas somente desta grande confederação de nações de um poder unificado e da decisão segundo leis de uma vontade unificada (KANT, 2004, p. 13).

É notável que, tanto na esfera individual quanto na social a noção de fio condutor da história para Kant admite percalços. 0 que pode parecer retrocessos com guerras e miséria, no ponto de vista Kantiano faz parte do sistema fundado na Razão. 0 a priori regulador deste sistema parece estabelecer um cálculo ou uma razão ao qual o homem está subordinado, pois sua espécie, para ter sucesso, precisa cumprir um programa cuja racionalidade já está dada.

Por isso, a oitava proposição de Ideia de uma História Universal de um Ponto de Vista Cosmopolita parece conter o plano geral da filosofia da história kantiana. Nela Kant considera que:

\begin{abstract}
[...] a história da espécie humana, em seu conjunto, como a realização de um plano oculto da natureza para estabelecer uma constituição política (Staatsverfassung) perfeita interiormente e, quanto a este fim, também exteriormente perfeita, como o único estado no qual a natureza pode desenvolver plenamente, na humanidade, todas as suas disposições. (KANT, 2004, p. 17).
\end{abstract}

O problema, segundo Kant (2004), é saber que a experiência revela algo que indique um curso de um propósito natural. A resposta é que há muito pouco a sugerir isso, o tempo transcorrido da história ainda é muito pouco de forma que somente a pequena parte da humanidade que o percorreu permite determinar, de forma precária, uma relação entre parte e todo. Mas, Kant parece satisfazer-se com o princípio geral da constituição sistemática da estrutura e o pouco que se pôde observar para se assegurar que esse ciclo 
natural existe. Ele observa certa artificialidade presente nas relações entre os Estados daquela época, pelo fato da atenção redobrada à cultura interna, para não perder poder e influência uns diante dos outros.

Este diagnóstico revela os propósitos ambiciosos dos Estados e por isto mesmo revela, também, ao menos, a manutenção da finalidade da natureza. Ainda no seu diagnóstico, Kant observa que a liberdade civil já não permitia desrespeitos sem que haja reações de todos os ofícios, e sem que por meio disto o Estado perca força nas relações externas. Ele nota que a liberdade se estende de forma que a liberdade individual do cidadão, desde que em coexistência com a liberdade do outro, está dentro de um contexto geral de modo que qualquer ameaça reflete, também, nas atividades gerais exercidas na liberdade dos demais. Desta forma, as restrições vão dando lugar a liberdade universal e assim surge aos poucos o iluminismo.

0 estado e os governantes devem ascender a influencia do iluminismo. É por meio dele que a ideia de manutenção do todo se afirmará e finalmente poderá se realizar o propósito supremo da natureza: “um Estado cosmopolita universal, como o seio no qual podem se desenvolver todas as disposições originais da espécie humana” (KANT, 2004, p. 19).

É depois de ler o diagnóstico de Kant, em que o filósofo aponta em sua época um estágio em que o estado ainda sofre com os antagonismos, que pode-se entender o que ele quis dizer com os edifícios ainda em ruínas no capítulo intitulado História da Razão
Pura de dito no começo deste item. Para tentar elucidar melhor seu programa filosófico, Kant convida a observar a história grega que, segundo ele, conserva todas as outras histórias que lhes são anteriores ou contemporâneas. Kant (2004, p. 20) afirma que fora este "público instruído" - os gregos - tudo é "terra incógnita" e que a história de outros povos, que não os gregos, só pode começar no momento em que se colocaram em relação a eles.

Assim, grande parte dos povos só pode ser situada na história no momento em que são circunscritos no contexto da cultura ocidental de origem grega. Kant exemplifica com o povo judeu na época de Ptolomeu com a tradução da bíblia para o grego e com Tucídides que, segundo Hume, é o único começo de toda história.

O que fica claro em Kant é a tensão entre o particular dos interesses pessoais, paixões, vícios, etc., e o universal do plano da natureza seguindo uma Razão. 0 resultado desta tensão é a progressiva batalha para o estabelecimento do Estado como lugar em que a liberdade pode ser vivida plenamente. Para isso, é necessária uma constituição que regule as ações dos homens e as relações entre os Estados na visada de um Estado Cosmopolita Universal. A Razão é o fator constante e a priori neste processo, ela é o eixo iluminista que de ruptura em ruptura mantém o sistema na direção do desenvolvimento. Neste sentido, o fio condutor da história universal, do ponto de vista kantiano, se confunde com o próprio processo de esclarecimento cuja plenitude, a espécie humana ainda não alcançou. Ao acreditar na plenitude e na liberdade do homem, Kant demonstra uma visão otimista para espécie humana.

\section{HEGEL E O FIO CONDUTOR DIALÉTICO DA RA- ZÃO NA HISTÓRIA UNIVERSAL}

Hegel (1995) fala de uma "marcha racional" necessária ao espírito universal em que os diversos

povos percorrem seguindo uma poderosa vontade de Deus que rege o mundo. Diante desta perspectiva 
duas dimensões se abrem ao entendimento: a humanidade como aspecto universal, e seu aspecto particular, a saber, o homem. Esta distinção é importante, pois apresenta um elemento admirável do programa filosófico de Hegel que é a contradição entre um absoluto e um particular (determinado). Este particular não está no mundo por acaso, nem ao acaso, mas, em sua particularidade, é determinado e sujeito a uma ordenação regida por leis da natureza e perceptíveis somente pelos homens. Esta ordenação é a própria marcha da razão buscando a realização do espírito.

Logo, pode-se notar uma progressão realizada pela marcha; ao usar o termo progressão lança-se, propositalmente, luz na questão temporal implícita nos passos da razão, onde se dá a característica de indistinção da filosofia e da história no pensamento de Hegel. É por esta via que o filósofo apresenta uma filosofia da história universal encarada de três formas: a história original, a história refletida, e a filosófica. A estratégia de Hegel ao marcar estes três modos de história é pensar uma filosofia da história universal de acordo com o progresso racional da humanidade.

Sendo assim, a história original é entendida em um caráter de imaturidade onde as crônicas ou os relatos de um povo são uma espécie de representações das próprias experiências vividas ou transmitidas como histórias:

\begin{abstract}
Os historiadores fixam o que transcorre de forma fugaz e inscrevem-no no templo de Minemósine para a imortalidade. Os mitos, as canções populares e as tradições dever ser excluídos dessa história original, pois eles são ainda modos obscuros e, por isso, apropriados à imaginação de povos de espírito confuso. (HEGEL, 1995, p. 11).
\end{abstract}

Aqui nota-se que, em termos de progresso na perspectiva hegeliana, existe uma racionalidade cuja indissociabilidade entre cotidiano e história marca o modo ainda confuso do pensamento histórico.
Cabe dizer que na história original ainda não há um distanciamento entre a vida e o fato histórico e, por isso, não permite uma reflexividade diante do elemento histórico. Só se alcança tal distanciamento como ultrapassagem do presente, "não com relação ao tempo, mas ao espírito”, na história refletida. Entre história geral, pragmática, crítica e, diga-se, transicional ${ }^{1}$, encontra-se a separação entre sujeito e história possibilitando pensá-la diferenciando: 1) os princípios destacados, os conteúdos, o tipo de história e a metodologia (história geral); 2) as reflexões do passado para as vivências e ações pragmáticas do presente (pragmática); 3) o julgamento das narrativas históricas, suas investigações e juízos de credibilidade (crítica); e 4) a linha ou fio condutor que liga "algo parcial" a um "ponto de vista geral" que ensaia a passagem para a história filosófica através do ordenamento entre o caráter externo da história e a "alma interior que dirige os acontecimento e ações".

Chega-se, então, à história filosófica, final do percurso onde há a concretização da Razão. Tem-se nesse momento, o encontro do espírito com suas qualidades intrínsecas ou seu fim em si mesmo, ou seja, a liberdade. Hegel pontua que a "razão governa o mundo e que, portanto, a história universal é também um processo racional” (HEGEL, 1995, p. 17). No bojo desta afirmação encontra-se uma noção de razão afastada do lugar de pressuposição ou a priori que se encontra em Kant, e entendida como substância, força infinita, "em si mesma a matéria infinita de toda forma de vida natural e espiritual” além de forma infinita que realiza seu próprio conteúdo. Entretanto, se afastar da razão como um pressuposto não indica necessariamente, como observou Hyppolite (1995, p. 40), uma oposição entre "razão pura e o elemento empírico, mas entre a vida e o estático, entre o vivo e o morto".

Deixando o lugar de pressuposto para tornar-se pressuposto de si mesmo, a razão não pode ser mais

\footnotetext{
1 Nomeei transicional o quarto tipo de história refletida. A escolha por este nome se dá pelo seu caráter destacado por Hegel ao afirmar que "ela constitui uma transição para a história universal filosófica". (HEGEL, 1995, p. 16).
} 
entendida como um ideal, ou algo que pode ser encontrado. Seu caráter infinito nutre-se de si mesmo e abre uma nova dimensão onde universal e particular de dissociam. De acordo com Hegel (1995, p. 17) a razão não carece da nutrição por elementos externos, “ela própria realiza sua finalidade e a faz passar do interior para o exterior, não apenas no universo natural, mas, também, no universo espiritual - na história universal." Esta ideia de razão comporta em si as manifestações do mundo, dentro de um destino realizado na "marcha racional" na direção da liberdade.

Hyppolite (1995, p. 43) destaca que a ideia de destino, juntamente com a de positividade, compõem o cerne da visão hegeliana de mundo em que podemos depreender desses entendimentos como os de um destino de um povo, de um indivíduo, ou de um destino geral.

Esta razão, ao cumprir o destino e tendo como finalidade e qualidade em si mesma a liberdade, trava uma luta de superação de si em um movimento progressivo que é o próprio progresso da consciência do homem. Nisto consiste a determinação da história, pois o objetivo final do universo é sua própria realização. Ora, volta-se aqui a dois campos importantes no contexto do entendimento do ponto de vista de Hegel sobre história: o campo das determinações e o campo do universal. Ao pensarem-se as ações dos indivíduos e as finalidades que as determinam, o particular ou a "atividade que os mobilizam, que lhes dá existência" (HEGEL, 1995, p. 27), encaminhadas pela "necessidade, o instinto, a tendência e a paixão", estão circunscritas em um objetivo geral, ou seja, espírito cuja essência e substância são a liberdade.

O espírito é em si mesmo e por si mesmo, segundo Hegel ele não possui unidade fora de si, ele é por si mesmo. Isto define a autoconsciência do espírito ou a consciência de si mesmo que marca a coordenada do progresso histórico. Hegel (1995, p. 24) aponta para dois aspectos na consciência: "primeiro, o fato de que sei; segundo, o que eu sei." Na consciência de si estes dois aspectos coincidem, o espírito conhece a si mesmo e, concomitantemente, volta-se para si no intuito de produzir o que se é em si. Assim a história universal é a representação do espírito no esforço de elaboração da autoconsciência contido neste processo: “a história universal é o progresso na consciência da liberdade - um progresso cuja necessidade temos de reconhecer." (HEGEL, 1995, p. 25)

Entretanto, até agora, o princípio e a natureza do conceito de espírito se mostrou apenas abstrata. Hegel destaca que tal princípio ou natureza é algo interior e como tal, mesmo sendo verdadeiro, não o é por completo. Ou seja, os fundamentos do espírito estão nos fundamentos e intenções, mas não ainda na realidade. Uma ação particular pode se unir a outra e ser expressa por um indivíduo; neste sentido ele carrega em si a realização e transformação necessárias em uma época: "percebemos que, na história universal, resulta das ações humanas algo além do que foi intencionado" (HEGEL, 1995, p. 31).

Por isso, é importante enfatizarmos a distinção feita por Hegel entre dois tipos de indivíduo para destacar a relevância de certas ações sobre outra. Tem-se, então, um certo tipo de indivíduo comum cujas necessidades imediatas, paixões e interesses, em cada ato voluntário segue um interesse particular; no entanto, apesar da motivação guiar-se apenas pelo objetivo do autor, ela não é sem ser cingida por algo além do que está na vontade e na consciência do mesmo. Esses atos particulares contém algo de universal, mas são impotentes, ou mesmo sem interesse em realizá-los como tal, se satisfazendo com o que conquistaram para si. Hegel fornece o exemplo de uma vingança que pode se desdobrar em consequências que se voltam contra aquele que a praticou.

Por outro lado, os indivíduos históricos universais, são os homens que através da contradição às leis e direitos, abrem a possibilidade de algo novo, de engendrar, a partir da destruição dos fundamentos de sua realidade, um conteúdo essencial, vantajoso e 
necessário. Na ação destes indivíduos há algo de histórico, que encerra um novo valor diferente em relação ao existente. "Esse valor geral é um momento da idéia produtiva, um momento da verdade, aspirando a si mesma” (HEGEL, 1995, p. 32).

Estes, para Hegel, são os grandes homens da história, pois, seus fins particulares contêm o "substancial da vontade do espírito" expressando a antítese que é o elemento necessário para a transformação de sua realidade, de acordo com o interesse da razão. Apesar de buscarem apenas a própria satisfação e de não terem em seus objetivos a consciência da ideia, os grandes homens, na história universal, serviam como uma espécie de "administradores do espírito universal” e esta condição lhes valiam um destino infeliz.

Portanto, com Hegel, podemos concluir que o interesse particular da paixão e participação no universal é, portanto, inseparável, pois o destino infeliz dos indivíduos históricos universais demonstra que: da atividade do particular dos seus interesses e de sua negação resulta o universal. Mas, como se dá a relação do particular com o universal? Hegel (1995) responde afirmando que no conflito, quem sofre desgaste é o particular que é em parte destruído, enquanto o universal se mantém ileso e intocável. Esta operação se dá devido ao que Hegel nomeou de astúcia da razão:

[...] deixar que as paixões atuem por si mesmas, manifestando-se na realidade, experimentando perdas e sofrendo danos, pois esse é o fenômeno no qual uma parte é nula e a outra afirmativa. 0 particular geralmente é ínfimo perante o universal, os indivíduos são sacrificados e abandonados. A idéia recompensa o tributo da existência e da transitoriedade, não por ela própria, mas pelas paixões dos indivíduos. (HEGEL, 1995, p. 35).

A astúcia da razão consegue resguardar a ideia, isto permite que as paixões atuem por si mesmas experimentando todas as conseqüências provenientes do conflito. Como resultado, algo se projeta em relevo, se excede como algo positivo e afirmativo diante das perdas na luta. Este é o preço do sacrifício pelo progresso da consciência da liberdade e que justifica as ações dos grandes homens na história. Na filosofia da história de Hegel o "direito do espírito universal ultrapassa todos os direitos especiais” (HEGEL, 1995, p. 38).

Esta precedência do espírito sobre os direitos especiais é estabelecida pela passagem das determinações para a sua realização, mediante a sua consciência e vontade que desde sempre estão imersas na vida natural. Portanto, do estado de natureza à realização do espírito representa a própria marcha gradual da história universal, cujo conteúdo é a consciência da liberdade.

Evolução do espírito não é simples como na vida orgânica, ele se dá no trabalho duro e incessante contra si mesmo. 0 objeto fundamental do espírito é sua própria essência, a liberdade. Tem-se aí o fio condutor da história, que transcorrem nos grandes períodos sem que se perceba a evolução. Hegel (1995, p. 55), divide estes períodos em três estágios que devem ser encarados de forma lógica e em seu caráter concreto de acordo com a fenomenologia do espírito: primeiro estágio consiste na imersão do espírito no natural; segundo estágio, é o avanço na direção da consciência de sua liberdade, neste período há a primeira separação da natureza, mas de forma ainda imperfeita e parcial; terceiro estágio acontece a elevação da liberdade do particular para o universal, à consciência de si e ao sentimento da própria espiritualidade.

É importante aludir que estes estágios são os três tempos da dialética, neles consistem o próprio movimento de contradição e superação do espírito no caminho da autoconsciência e liberdade. Cabe lembrar que o espírito é para si e em si mesmo e que por isso é seu próprio fim, dessa forma, no espírito está contido a sua possibilidade infinita, que no primeiro momento é só possibilidade, mas que encerra em si sua substância que, no curso do progresso, alcançará a concretização na realidade. 0 movimento de conservação e superação que ocorre nas contradições pode 
ser observado na forma como a questão da passagem do imperfeito para o perfeito, sem que a perfeição esteja ausente da imperfeição, aqui pode-se ver como a contradição não é uma negação que exclui o outro termo, mas o conserva dentro de si:

Assim, na existência real, o progresso surge como um avanço do imperfeito para o mais perfeito - o que não deve ser entendido abstratamente como apenas o imperfeito, mas como algo que é, igualmente, o contrário de si mesmo (o assim chamado perfeito), como um embrião e como um instinto. Da forma que está destinado a se tornar real; a dynamis aristotélica é também potentia, força e poder. a imperfeição como contrário de si é, em si mesma, a contradição que certamente existe, mas que logo é superada e resolvida. Ela é também o instinto, o impulso da vida espiritual para romper o invólucro da mera natureza, dos sentidos e de tudo que é alheio a ela, para chegar à luz da consciência, isto é, de si mesma. (HEGEL, 1995, p. 55).

Hegel (1995) demonstra a evolução dos períodos históricos com a própria história. Ele entende que nas sociedades orientais havia apenas um indivíduo livre, o déspota; essa liberdade, todavia, era arbitraria e bárbara, ou ainda, mansidão da paixão "que é apenas contingência da natureza ou capricho” (HEGEL, 1995, p. 25).

Somente com os gregos é que a consciência de liberdade surgiu, entretanto, eles sabiam que só alguns poderiam ser livres e não o homem em geral. Os gregos possuíam escravos e precisavam deles para garantir a liberdade e existência. A consciência do homem livre como tal só veio com as nações germânicas cristãs, a partir desse período é que foi possível a tomada de consciência do homem livre como tal e que "a liberdade do espírito constitui a sua natureza mais intrínseca” (HEGEL, 1995, p. 24)
Nesta leitura de Hegel está presente a evolução histórica em três temos: 1) em que um único homem é livre, o déspota; 2) o mundo grego e romano onde alguns eram livres, mas precisavam dos escravos; 3) as nações germânicas que a ideia de liberdade abrange o homem como homem, ou seja, a liberdade está no homem em si.

A razão, no curso da evolução histórica segue uma espécie de natureza divina, ou melhor, a teodicéia que justifica Deus na história. Nesse sentido, a espiritualidade do homem encaminha-se para liberdade através da religião e da autoconsciência. Dessa forma, pode-se entender a razão como a própria busca da compreensão da filosofia na teodicéia de Deus em direção à ideia de liberdade no homem, ou melhor, a consciência de liberdade.

Assim, filosofia tem como interesse conhecer o processo de desenvolvimento da ideia de liberdade, ou melhor, a consciência de liberdade como realização do espírito pela razão. A ideia na qual se reflete a história universal está desde sempre no homem; seu progresso se dá à custa das abstenções das paixões e das contingências naturais para tornar-se consciente de si. Portanto, a história universal é a própria percepção da reconciliação com a realidade através do desenvolvimento do conceito de liberdade.

O pensamento é agora o estágio a que o espírito chegou. Ele contém a reconciliação em toda a sua essencialidade, já que se trata do exterior com a reivindicação de que essa existência tenha a razão em si como sujeito. 0 espírito reconhece que a natureza, o mundo, precisa ter uma razão na existência, já que Deus, sabiamente a criou. (HEGEL, 1995, p. 361).

\section{CONSIDERACÕ̃ES FINAIS}

Diante do exposto, a leitura iluminista kantiana e hegelina da História Universal, obedece a programas que se distinguem apesar de partirem do princípio: a Razão como elemento essencial. Estas duas linhas 
de pensamento marcam modos de leituras de textos gregos antigos, cada uma seguindo os princípios das racionalidades engendradas por esses autores.

Quando Kant coloca o homem como subordinado a uma Lei moral que segue a Razão, ou seja, de acordo com um plano natural a priori e independente da espécie humana (que, no entanto depende deste plano), ele projeta a liberdade como sentido da bússola da história. Os antagonismos presentes na coexistência humana servem como provas para a conduta social pautada nesta liberdade. 0 estado entra como esse projeto em que se podem desenvolver as potencialidade humanas de acordo com uma conduta que segue a Lei moral. Mas qual o lugar dos gregos? Os gregos inauguram a sistematização das ações humanas no que se pode chamar de Estado, inclusive com a formação e degeneração de um corpo político posteriormente herdado pelos romanos.

O que está em jogo na perspectiva kantiana é a teleologia da espécie humana através da determinação das ações do homem pela Razão. 0 plano já estava dado e sua operacionalização assegurada pelo sistema. Dessa forma, o particular das ações e condutas é sempre situado de acordo como universal da Razão transcendental anterior a sua lógica. Giannotti (2004, p. 153) auxilia a entender isso ao dizer que "uma nova atividade de espírito vem acertar um encaixamento de conceitos, suponhamos, 'a mortalidade de Sócrates', para transformá-lo na proposição Sócrates é mortal”. 0 que fica posto neste comentário é a própria chave de leitura que Kant dispõe para que se leia um texto antigo dentro da História Universal.
Diferentemente, Hegel põe uma determinação da História que fornece outra forma de ler textos antigos. Para Hegel a Razão escreve a História e os homens ficam diluídos no curso progressivo dela, lutando pela conciliação de suas motivações individuais com o Espírito. Ao final deste percurso, a autoconsciência alcança a liberdade que é a própria substância do espírito presente desde sempre. A Grécia, como já visto, é o momento em que esta liberdade é considerada para vários homens dentro do que se pode entender como estado, e neste sentido, há uma contradição em relação ao momento despótico anterior. É por isso que, de acordo com Hyppolite (1995, p. 32), pode-se compreender que "para Hegel a República de Platão não fosse uma utopia, pois traduzia conceptualmente o ideal imanente à cidade antiga."

A tentativa feita neste artigo foi de esquematizar uma forma de compreensão de História Universal segundo Kant e Hegel que fornece um lugar a partir do qual pode-se ler textos antigos de acordo com certa racionalidade. Inúmeros aspectos foram deixados de lado, em nome de uma ênfase dada no modo como os dois filósofos destacados tratam da Razão e da relação entre o universal (Razão, espírito - para Hegel, e natureza - para Kant) e o particular (o indivíduo, suas paixões e contingências). Procurou-se assim, seguir este caminho como um fio condutor do texto no intuito de organizá-lo separando dois possíveis lugares nos quais pode-se ler textos antigos.

\section{REFERÊNCIAS}

GIANNOTTI, J. A. Kant e o espaço da história universal. In. KANT, Immanuel. Idéia de história universal de um ponto de vista cosmopolita. Organização: Ricardo R, Terra; tradução de Rodrigo Naves, Ricardo R. Terra. São Paulo: Martins Fontes, 2004. 
HEGEL, G. W. F. Filosofia da História. Tradução de Maria Rodrigues e Hans Harden. Brasília: Universidade de Brasília, 1995.

HEGEL, G. W. F. Enciclopédia das Ciências Filosóficas em Epítome vol I. Lisboa: Edições 70, 1988.

HYPPOLITE, Jean. Introdução à Filosofia da História de Hegel. Tradução de José Marcos Lima. Rio de Janeiro: Elfos, 1995.

KANT, Immanuel. Crítica a Razão Pura. Tradução de Manuela Pinto dos Santos. Lisboa: Fundação Calouste Gulbenkian, 2001.

KANT, Immanuel. Idéia de história universal de um ponto de vista cosmopolita. Organização: Ricardo R, Terra; tradução de Rodrigo Naves, Ricardo R. Terra. São Paulo: Martins Fontes, 2004.

KANT, Immanuel. Crítica da Faculdade do Juízo. Tradução V. Rohden \& A. Marques. 2. ed. Rio de Janeiro: Forense Universitária, 2005. 